\title{
Editorial
}

\section{Evolving trends in plant-based drug discovery}

Traditional medicine (TM) and herbal industry provide livelihood and health security to over $80 \%$ population in developing economies. World trade in herb-based medicine stands at US\$ 120 billion and is expected to reach US\$ 7 trillion by 2050 (http://www.nmpb.nic.in/). It is believed that nearly 6000 species of plants are extensively used in traditional, folk, herbal and modern medicines as a source of conventional pharmaceuticals, either as raw material or source of extracted active ingredients or as a chemical lead for the synthesis of valuable biomolecules (Lavania, 2005). Researches on herbal drugs and TM inspired approaches to drug discovery have occupied central stage in academia and industry. The knowledge base of traditional systems and phylogeny/metabolic pathway guided leads for active molecules combined with modern science and reverse pharmacology path is paving new functional leads (Patwardhan \& Mashelkar, 2009).

The Evolution of Drug Discovery as an interdisciplinary endeavour with an industrial base, the drug research per se is not much older than a century (Drews, 2000). Whereas isolation and purification of the biologically active ingredients from plants, such as morphine in 1815 (Sertüerner, 1817) and Papaverine in 1848 from opium extract were achieved much earlier, but their antispasmodic properties could be discovered only in 1917 (Sneader, 1985). Such developments underpinned the significance of plants in medicine and laid the foundation for scientific exploration of plants as potential resource for development of drugs. But the Discovery of Penicillin by Alexander Fleming (1929), followed by identification of a large number of antibiotic substances opened the door to a new era in the treatment of bacterial infections and foundation of modern medicine.

Over 120,000 phytochemicals from higher plants have been examined for their therapeutic potential worldwide. During 1991-1995 around 200 NCEs (new chemical entities) were introduced globally, of which 10 (2\%) led to the drug development and commercialization (Dev, 1997). Approximately $60 \%$ of the antitumour and anti-

(Email: lavaniauc@yahoo.co.in) infective agents in use are of natural product origin (Cragg et al., 1997). Production of plant-based modern drugs has become an important segment of the pharmaceutical industry. Notable single active molecules currently in use are morphine, codeine and papaverine, quinine, quinidine, hyoscine and hyocymine, colchcine, digoxin, lanatoside, berberine, vinblastin, vincrystin, reserpine, recinamine and deserpidin, diosgenin, sennosides, podophylotoxin, artemisinin, taxol, pilocarpine and sylmarine (Handa, 1992; Patwardhan et al., 2004).

\section{TM inspired bioprospection and drug discovery}

Though contemporary medicine is currently the mainstream of medical practice, but nearly all cultures, from ancient times to today, have used plants for medicine, exploiting their secondary metabolites as pharmaceutical agents. Over 100 types of traditional systems of medicine (TSM) identified by the World Health Organization (WHO) are in vogue worldwide today, and continue to be the tradition of every country, in spite of the advancement of modern medicine and the discovery of new and novel drugs in recent times. TMs are the precious cultural heritage of the different societies of the world. These systems of medicine have a strong doctrinaire base, well documented, and recognized or codified indigenous systems of medicine. They are heavily dependent on plant-based drugs, although drugs of mineral and animal origin are also utilized for total health care management. The majority of the population in developing economies still relies on TM for their health care needs, and the popularity of TM is fast spreading in the industrialized countries (Singh et al., 2012).

However, the usage of natural substances directly as therapeutic agents in modern medicine has sharply declined from the predominant position held in the early decades of 20th century, but with the advent of modern analytical tools and progress in biological understanding, search for bioactive molecules from nature continues to play an important role in fashioning new medicinal agents (Dev, 2010). 


\section{Traditional and ethnomedicinal knowledge}

Among the TSM practiced all over the world, Ayurveda of India has a documented history dating back to 1500 BCE (Singh et al., 2012), Chinese Medicinal Plants (texts from 4th Century BC) and Unani medicine (Kitab-Al-Shifa, the Magnum Opus of Avicenna 980-1037 AD) - (Evans, 2009). Another form of traditional medicament, variously termed as ethno, tribal or folk medicine (Jain, 2004), is used by tribals and aboriginals inhabiting rural or remote inaccessible areas. These forms of medicines are generally uncoded or unrecorded and perpetuated by word of mouth among the communities. In a few geographic regions of the world (e.g. remote areas in Africa, Asia and South America) that are not yet affected by fast-encroaching modern civilization, there exists a wealth of information on the properties of plants built up by the people in primitive societies over millennia (Schultes, 1991).

\section{Traditional knowledge digital library}

Traditional medicinal knowledge has proved to be very valuable in the discovery of many potential medicaments. Most of the phytopharmaceuticals used as therapeutic agents throughout the world today have been developed based on cues obtained from ethnobotanical or traditional uses over thousands of years (Dev, 1997). Such information still continues to be the obvious choice for bioprospection in the current research programmes of many countries of the world. A good deal of research has lately been done to prove the concepts, therapeutic regimens, therapies and other modalities pertaining to TM. As a result, certain excellent leads have emerged, including Guggulu (gum resin of Commiphora) for hypercholesterolaemia, Boswellia for inflammatory disorders, Arjuna (Terminalia arjuna) for cardioprotection, turmeric (Curcuma longa) for wound healing and antioxidant and anticancer properties, Kutaki (Picrorbiza kurroa) for hepatoprotection, Kshaara-Sutra (a medicated thread coated with herbal alkaline drugs - ash of Achyranthus ascera, latex of Euphorbia nerufolia and powder of $C$. longa in a specific order for anorectal disorders), and Pancha Karma for neurodegenerative disorders (Katiyar, 2010), but most of such knowledge is either unrecorded or scattered in remote texts.

Therefore, in order to lay strong foundation for systematic progress of traditional knowledge inspired modern drug development, as well as protection of IPR, the Council of Scientific and Industrial Research (CSIR), Ministry of Science and Technology, and Department of AYUSH, Ministry of Health and Family Welfare, Government of India, initiated a major project in 2001 named The Traditional Knowledge Digital Library (TKDL). TKDL is created on the codified traditional knowledge existing in local languages on Indian Systems of Medicine (Ayurveda, Unani, Siddha and Yoga) by scientifically converting and structuring the available contents of ancient texts into five international languages. As on date, the TKDL database has 97,337 formulations in Ayurveda, 1,75,150 formulations from Unani, and 23,016 formulations from Siddha. A total of 0.29 million medicinal formulations have already been transcribed (www.csir.res.in).

\section{Using evolutionary tools to search for novel psychoactive plants}

Halse-Gramkow et al. (2016) has advanced a complementary approach that utilize phylogenetic analyses based on traditional uses or known chemistry to identify lineages in which desired properties are most likely to be found. It is suggested that novel discoveries of plant bioactivity from these approaches can aid the development of treatments for diseases with unmet medical needs, such as neurological disorders. Combining ethnodirected approach with phylogenetic analyses presents a promising methodology to highlight lineages with desired chemical or medicinal properties (Wink, 2003; Rønsted et al., 2012; SaslisLagoudakis et al., 2012).

\section{Lesser-known group of plants}

Whereas, researches on development and bioprospection for plant-based drugs have largely been limited to higher plants, mainly because of their prominent appearance to the eyes, but a careful examination of literature show that lower plants do offer unique active principles not known in higher plants. Therefore, in this volume a due emphasis has been made about the prospective potential of Algae, Bryophytes and Pteridophytes as the promising resources of new medicines. In an earlier issue of $P G R$ (August 2005) dedicated to medicinal plants, the group of Lichens and Mushrooms were covered, and the gap left with respect to other lower plants has been filled this time.

There is strong belief that judicious comparison of various traditional systems, including ethnomedicinal claims across the ethnic groups, wherein the same plants help cure similar ailments across the communities could be a prospective approach for scientific validation and traditional knowledge inspired drug discovery.

In this special issue on medicinal plants, in addition to due treatment to two major medicinal plants, Catharanthus and Mucuna from $P G R$ and cultivation perspective, specific emphasis has been laid to provide a larger overview of the area ranging from ancient plant introductions in the enrichment of traditional medicinal knowledge, significance of plant metabolites and metabolic pathway that can be 
helpful in biotransformation and enhanced production of key metabolites, disease-free cultivation of quality raw material through better management of plant diseases, and phylogeny-guided bioprospection.

I am extremely grateful to all the contributors and expert reviewers for their cooperation, to Robert Koebner, the former Editor-in-Chief for prompting me to take the task and Theo Van Hintum the present EIC of PGR: C \& U for his inspiring support and opportunity to edit this special issue. My special thanks to Stephanie Sacharov, Secretary of the journal for her sustained organizational support.

\section{Umesh C. Lavania ${ }^{1,2}$ \\ ${ }^{1}$ Department of Botany, University of Lucknow, Lucknow-226007, India \\ ${ }^{2}$ CSIR-Central Institute of Medicinal and Aromatic Plants, Lucknow-226015, India}

\section{References}

Cragg GM, Newman DJ, and Snader KM (1997) Natural products in drug discovery and drug development. Journal of Natural Products 60: 52-60.

Dev S (1997) Ethnotherapeutics and modern drug development: the potential of Ayurveda. Current Science 73: 909-928.

Dev S (2010) Impact of natural products in modern drug development. Indian Journal of Experimental Biology 48: 191-198.

Drews J (2000) Drug discovery: a historical perspective. Science 287: 1960-1964.

Evans WC (2009) Trease and Evans Pharmacognosy, 16th edn. Philadelphia, PA: Elsevier Saunders Ltd.

Fleming A (1929) On the antibacterial action of cultures of a Penicillium, with special reference to their use in the isolation of B. influenzo. British Journal of Experimental Pathology 10: 226-236.

Halse-Gramkow M, Madeleine Ernst M, Nina Rønste N, Robert R, Dunn RR, Haris C, Saslis-Lagoudakis CH (2016) Using evolutionary tools to search for novel psychoactive plants. Plant Genetic Resources 14: 246-255.

Handa SS (1992) Medicinal plants-based drug industry and emerging plant drugs. Current Research on Medicinal Aromatic Plants 14: 233-262.
Jain SK (2004) Credibility of traditional knowledge: the criterion of multilocational and medicinal use. Indian Journal of Traditional Knowledge 3: 137-153.

Katiyar CK (2010) Indian initiative in the revival of traditional systems of medicine: an overview and recent leads from Ayurveda. In: Ram HYM and Tandon PN (eds) Science in India: Achievements and Aspirations. New Delhi, India: Indian National Science Academy, pp. 243-256.

Lavania UC (2005) Pharming plant genetic resources. Plant Genetic Resources 3: 81-82.

Patwardhan B and Mashelkar RA (2009) Traditional medicineinspired approaches to drug discovery: can Ayurveda show the way forward? Drug Discovery Today 14: 804-811.

Patwardhan B, Vaidya ADB and Chorghade M (2004) Ayurveda and natural products drug discovery. Current Science 86: 789-799.

Rønsted N, Symonds MR, Birkholm T, Christensen SB, Meerow AW, Molander M, Mølgaard P, Petersen G, Rasmussen N and Van Staden J (2012) Can phylogeny predict chemical diversity and potential medicinal activity of plants? A case study of Amaryllidaceae. BMC Evolutionary Biology 12: 182. doi: 10.1186/1471-2148-12-182.

Saslis-Lagoudakis CH, Savolainen V, Williamson EM, Forest F, Wagstaff SJ, Baral SR, Watson MF, Pendry CA and Hawkins JA (2012) Phylogenies reveal predictive power of traditional medicine in bioprospecting. Proceedings of the National Academy of Sciences of the United States of America 109: $15835-15840$.

Schultes RE (1991) The reason for ethnobotanical conservation. In: Akerele O, Heywood V and Synge H (eds) Conservation of Medicinal Plants. New York: Cambridge University Press, pp. 65-75.

Sertüerner (1817) Ueber das Morphium, eine neue salzfähige Grundlage, und die Mekonsäure, als Hauptbestandtheile des Opiums. Annalen der Physik 55: 56-89. doi: 10.1002/ andp. 18170550104.

Singh J, Lavania UC and Singh S (2012) Indian traditional and ethno-medicines from antiquity to modern development. In: Singh RJ (ed.) Genetics Resources and Chromosome Engineering of Medicinal Plants: Medicinal Plants, vol. 6. Boca Raton, FL: CRC Press, pp. 53-86.

Sneader W (1985) Drug Discovery. New York: Wiley.

Wink M (2003) Evolution of secondary metabolites from an ecological and molecular phylogenetic perspective. Phytochemistry 64: 3-19. 